\title{
¿Se puede hablar de transhumancia en la zona atacameña?
}

Gustavo Le Paige*

No hay duda posible que los primeros hombres que llegaron a establecerse en la zona ahora llamada de San Pedro de Atacama vinieron de otras partes con elementos culturales ya constituidos entre los que destacan las "pre-projectil point" de Ghatchi y Valle Chico, los inmensos bifaces y monofaces de Altamira (estación del ferrocarril), excluyendo por ahora las bolas esferoidales de Tchasquir, en San Pedro de Atacama. Este movimiento se detuvo seguramente en aquella época, pues se establecieron al lado de la antigua e inmensa laguna del actual Salar de Atacama y en los pantanos o selvas de la actual zona salitrera de Altamira. Cuando se multiplicaron lograron desarrollarse ampliamente hasta destruir la fauna de caza. Pudo cambiarse el clima u ocurrió la catástrofe originaria de la formación del salitre. ¿Se transformaron lejos de la zona? Eso no podemos probarlo todavía, pero podemos asegurar desde ya dos hechos. El primero es que el hombre del Paleolítico Inferior radicado en la actual zona salitrera se extinguió bruscamente en la región, sin dar hasta hoy la posibilidad de saber si se extinguió in situ o si "transhumó" hacia otras zonas. El segundo, es que el grupo que habitó la propia zona del actual Salar de Atacama permaneció en el lugar cambiando sus hábitats a poca distancia, ocupando siempre varios sitios en un ambiente cercano de su primer establecimiento.

Estos dos últimos sistemas de ocupación de la zona parecen ser iguales, pero en la realidad son distintos. En efecto, el primer sistema consiste en abandonar los sitios y establecerse algo más al lado por razones tan obvias como pudo ser el descenso del nivel de las aguas de la laguna y el consiguiente acercamiento de los cazadores a las nuevas orillas. Mientras que el segundo sistema consiste en la continuidad de la ocupación en el sitio primitivo por sus importantes características. Pero algunos grupos pequeños se establecen en varios sitios secundarios por razones obvias también, como pudo ser que el sitio primitivo se sobrepobló en una

* Museo de Arqueología, San Pedro de Atacama, Universidad del Norte. etapa en que la caza comenzaba a disminuir o que el tipo de fauna desaparecía de los alrededores del sitio primitivo y se necesitaba cazar a otros tipos de animales en varios lugares distintos, para asegurar la sobrevivencia (se entiende que en esta época sólo existen como sistema de alimentación las prácticas de caza y la recolección que también van cambiando simultáneamente). Estos factores forzarán a la gente a cambiar su sistema social, pasando de la vida clánica a la vida de grupos pequeños, siempre relacionados con el grupo central primitivo hasta llegar a la independencia de cada grupo menor, casi únicamente familiar; un proceso similar ocurrirá en el Neolítico, cuando las familias se reúnan en pueblos importantes alrededor del corral común, para luego dividirse en dos grupos y más, hasta terminar con la dispersión de las familias, cada una en sus potreros o en sus andenes de cultivos, con sus corrales particulares. Esta separación de grupos permitirá también el cambio de tipos de proyectiles y herramientas de trabajo, sin necesidad de plantearse la llegada de nuevos pobladores que llegarían a ocupar los antiguos o nuevos sitios. Nunca se encuentra un sitio abandonado que haya sido ocupado por otro grupo nuevo que le sucede, pero sí hay muchos lugares que presentan grupos que empiezan la ocupación, con tal tipología en relación a su sitio "madre", donde va muriendo tal tipología por los motivos ya explicados, y desarrollando una nueva tipología exigida por el nuevo ambiente. A veces podremos decir que este nuevo tipo o éxito empezó en el nuevo sitio y fue introducido en el sitio "madre" por la gente que cambió de sitio, pero que ha conservado todavía las relaciones con ellos. Este fenómeno fue de lo más espectacular al principio del desarrollo de la punta de proyectil tetragonal, que explica el régimen de lluvias, un cambio de ecología y un cambio de fauna, principalmente en la tercera época del Paleolítico, caracterizada por el uso de la jabalina, aves acuáticas y animales pequeños. La primera época corresponde a las puntas gruesas de picana con animales pesados como el mastodonte y la segunda se caracteriza por el uso de lanzas (bifaces medianos) asociados a animales medianos como el guanaco, vicuña, etc. 
Entonces, ¿podremos hablar de transhumancia? Según el sentido de la palabra la transhumancia existió en el hecho en que se ocupó la zona, pero ¿en el sentido de que desde aquí salieron a poblar otras zonas? No podemos asegurar por la falta de estudios comparativos entre las diferentes regiones de las Américas. Tampoco de los Andes Centrales solamente. Además, por la falta de criterios similares para el tratamiento tipológico del material lítico, que ayuden a exprimir bien estas ideas.

En conclusión, sería mucho mejor hoy día no hablar de transhumancia, pero sí de desplazamientos de poblaciones en la misma región, bastante reducida, pues la palabra "transhumancia" no existe en el diccionario español en 28 tomos, pero sí existe la palabra transhumar, la cual significa: "el paso de los pastores con sus tropas de ganado del campo hacia las montañas y viceversa, según las estaciones de invierno y verano", o "pasar el ganado de lana desde las dehesas o extremos en que pasta a las montañas para veranear, y al contrario".

$\mathrm{Al}$ ver el sistema de pastoreo que existe actualmente en la zona, es normal que quisiéramos utilizar la palabra transhumar -forjando esta palabra "transhumancia"- para aplicarla a este modo de vida. ¿Tenemos ahora en esta situación la respuesta descrita en el diccionario? La respuesta es no. Tenemos otros sistemas y variados que son propios del pastoreo en todas las épocas del año, que consisten en amplios recorridos en una zona larga y estrecha de una extremidad a otra, en un perpetuo vaivén. Hay otros sistemas que mantienen sus ganados en una zona aproximadamente de igual largo y ancho con un punto de residencia en un pueblo específico. ¿Podemos asegurar que esto fue igual al pasado? Aquí se complica la cosa: ¿No habría otro modo, otras palabras, para explicar el desplazamiento de la gente en su zona? Algunos investigadores dirán que la palabra "transhumancia" debería significar todo esto. Lo sentimos mucho, pero debemos contestar que cada uno debe referirse al diccionario oficial, para saber bien cuál es el significado de nuestras palabras.

Como ya lo hemos exprimido, necesitamos ponernos de acuerdo antes de tratar este asunto. Según el diccionario la palabra transhumar se aplica sólo para las prácticas del pastoreo. En oposición, algunos investigadores exponen que tienen derecho a ampliar el sentido de la palabra y aplicarla a dos variedades distintas de vida, la primera para los cazadores primitivos, quienes desde su hábitat salen a cazar a otros sitios según las estaciones anuales, y la segunda para los pastores, en el sentido antes descrito por el diccionario, pero también para el traslado de ganado por cualquiera estación del año, en lugares limítrofes de su pueblo. Personalmente no me siento autorizado para cambiar el sentido reconocido oficialmente para una palabra, pero proponemos dos soluciones:

1. En vista del desarrollo del conocimiento de los orígenes de la humanidad, nos damos cuenta que no tenemos palabras adecuadas para los diferentes sistemas de vida de los cazadores nómades, de los cazadores recolectores de raíces y frutos, de los primeros pastores con rebaños comunes, de los pastores individuales que se reservan zonas propias de pastoreo. Por todo esto, necesitamos que forjemos nuevas palabras para no equivocarnos cuando nos planteamos las variedades de sistemas, conservando la palabra "transhumar", con el sentido reconocido por la Academia.

2. Si se acepta que tenemos el derecho de utilizar esta misma palabra para designar todas estas variedades, se necesita de todos modos ver las diferencias de su aplicación según sean las diversas situaciones presentadas. ¿Cómo lo haremos? Utilizando expresiones diferentes: ocupación progresiva de la región, cambio de sitios de habitación definitivos o transitorios, centros habitacionales con sus estancias de caza de invierno o de verano, zonas limítrofes del hábitat para el pastoreo, doble hábitat de pastores que alternan del uno al otro durante todo el curso del año, cualquiera que sea su estación.

Insistimos en esto, para tratar de evitar las mismas dificultades que tenemos ahora entre nosotros cuando hablamos de las industrias líticas del Paleolítico o Precerámico. La misma situación surgirá ante el hecho sencillo que los sistemas antes descritos los encontramos en la zona abarcada por nuestras investigaciones arqueológicas. La prueba la tenemos en los 326 sitios del Paleolítico que hemos encontrado (provincia de Antofagasta) -sin hablar de los 102 sitios en el suroeste de Bolivia-, con sus 295395 artefactos líticos, sin contar talleres y debitage conservados y clasificados en el Museo de San Pedro de Atacama, como también de los 67 pueblos, hábitats y estancias de cazadores y pastores que tenemos en la zona. En nuestros tiempos actuales ipodremos decir que existe un solo sistema de transhumancia? 
No. El sistema trecemal (forjando la palabra) de Machuca, pueblo ubicado a $4000 \mathrm{~m}$ de altura, con imposibilidad de agricultura es totalmente distinto al practicado por don Juan Vilca en el ayllu de Guatin a $2 \mathrm{~km}$ de Machuca, o de los agricultores de San Pedro de Atacama, encerrados por el desierto en donde utilizan sus pequeños potreros para el descanso de uno o dos días con sus rebaños. ¿Y Talabre, Camar, Socaire? Los pastores de aquí permanecen en sus pueblos, pues en sus puertas están las posibilidades del pastoreo. ¿Pasto muy pobre o escaso? Seguramente necesitan grandes extensiones de terreno, pero a su vez lo requieren sin necesidad de molestarse entre sí, de modo que cada uno esté seguro que no sentirá frustraciones posteriores.

Nuestra propia vida sacerdotal y misionera depende de estos sistemas. Los pobladores no están en su pueblo sino para tal o cual fiesta: fiesta patronal, Pascua, fiestas patrias, limpieza de los canales de regadío, etc. Entonces, estos sistemas deberían ser estudiados y aplicarles palabras como transhumancia, pero con la posibilidad de designar todas estas variedades. Igualmente para el Paleolítico se requiere del estudio de los sitios con sus estancias, y sus materiales líticos distintos o idénticos, con sus desechos líticos procedentes de trabajos diferentes, según el hábitat o la estancia de caza. En el primero hay trabajo de talla, en el segundo hay trabajos de retoque y de terminación de proyectiles. Todo esto comprueba el desplazamiento de los pobladores definitiva o transitoriamente. En las quebradas de Chaxas o de Socaire hay de siete a 10 sitios habitacionales. ¿Quién comprobará que los pobladores de tal o cual sitio van a ocupar en el mismo tiempo otros sitios? ... ¿Quién comprobará que los ocupan todos en forma separada en el espacio y tiempo? Unicamente el estudio de los artefactos: si han cambiado o evolucionado o si han permanecido iguales.

Para estudiar el problema que nos interesa hoy no sirve de mucho estudiar un sitio con vestigios de pircas, sino más bien se necesita de muchos yacimientos para proponer una teoría, comprobarla y aplicarla a otras zonas. Así tenemos estructuras seguramente del Paleolítico, del Mesolítico, del Neolítico, incaicas, coloniales y actuales. Naturalmente, cuando las ruinas son importantes, con restos de murallas destruidas pero lo suficientemente altas como para atribuirles su significado o su función, como también la manera de vivir de sus habitantes. Será, por lo tanto, más difícil si sólo se encuentran amontonamientos de piedras en medio de los cuales hay ciertas posibilidades de encontrar una semejanza con círculos de piedras. En Tulan dos de los tres fogones habitacionales fueron descubiertos afuera de lo que pensábamos eran círculos habitacionales, ipero estaban bajo un amontonamiento de piedras!

Al contrario, en otras partes se encuentran claramente estos círculos ... ipero sin nada más! ¿Dónde estarían las piedras de las capas superiores que legitimarían una muralla? Esto comprobaría la presencia de un hábitat, pero ¿estas piedras en círculo serían la única base de piedras en donde se levantaban chozas de ramas y de cueros? Esto designaría más probablemente una estancia de caza. Algunos investigadores "doctrinan" muy rápida o fácilmente cuando se trata de un caso, pero no es tan fácil cuando se encuentran tantas variedades de tipos distintos de instalaciones.

En el Paleolítico, es decir, sin presencia de cerámica, de esta zona que estudiamos, tenemos dos tipos de hábitats: el primero (no hablamos de prioridad en el tiempo) corresponde a habitaciones circulares agrupadas o juntas como en los casos de Ghatchi 1 y 2 y San Juan de Monturaqui. El segundo representa las mismas habitaciones circulares más o menos agrupadas, pero no juntas, distantes unas de otras por 10 o más metros hasta distancias de $100 \mathrm{~m}$. Pero también se registran solas o aisladas de cualquier otro hábitat. Del primer sistema de este segundo grupo tenemos el caso de Ghatchi en la loma 28 bis y en Valle Chico con un círculo, Tapus, Miniques, Lari, Tumbre, Miscanti, Calarcoco, Chaxas, Ojos de San Pedro con dos círculos cada uno; Puripica, Tulan, Algarrobilla 1 y 2, Altamira y San Martín con varios.

El Mesolítico es más difícil de definir, pues hay varios elementos nuevos que intervienen, y estos no son idénticos en todos los sitios. En las alturas va predominando el pastoreo y sólo a veces la agricultura, pero sin que exista una relación evidente con el hábitat. Las plataformas de cultivos están cercanas, pero no se disponen como en la época siguiente, es decir, en donde el hábitat posee corral propio en sus propios andenes. En esta época del Mesolítico ubicamos a Machuca, con sus círculos concéntricos, Cuno, Hatchar 1 y 2 (cerca de Socaire), como también los dos sitios clásicos de Socaire mismo, Tilocalar 3 (ruinas) y Taira. En cuanto a Guatin seguramente que se fecha en el Neolítico: las excavaciones realizadas por Serracino lo comprueban, sin excluir su pertenencia al final del Mesolítico y su origen más lejano aún. 
El Neolítico es mucho más claro y es difícil equivocarse sobre el gran número de ruinas como Lasana, Turi, Quitor (San Pedro de Atacama), Topain, Talikuma (Caspana), Calar, Tkiu-tchu (Toconao), Tapus 2, Quepi, Tilocalar 1, Tchapunaqui, Alto de Labra 1 y 2, Alto de Tocolén, Vilama 1 y 2, Santa Ana de Calarcoco, Catarpe 1, Cuesta de San Bartolo, Hatchar 3, Lavor, Oyrintor, Paniri, Quihusuma, Peine sitio oriental, y las ruinas actuales con sus tres épocas, Soncor, Zapar, Solor 4, Tulor 1 a 15, Coyo, Toconao y Socaire (también estos dos con sus tres épocas). Citamos a Camar para su época neolítica o colonial.

De la época incásica tenemos por lo menos "Catarpe Tambillo", su refugio y sus vigías como la de San Pedro, sobre el cerro de la sal, Oyrintor o recinto de defensa, el centro religioso en la silla entre el Licancabur y el Yariques, y los lugares votivos en la cumbre del Lascar, del Pili, del Pular, del Miniques, del Socompa, del Yariques, del Licancabur, del cerro Colorado, del San Pedro y San Pablo, del Paniri, del Miño.

De la época colonial necesitaría hablar de todos los pueblos surgidos después de la conquista española, como San Pedro de Atacama, Chiuchiu, etc. En particular es interesante el ayllu de Beter (San Pedro de Atacama), reservado al descanso de las mulas transportando cargas de Cobija a Uyuni o Cochabamba y viceversa.

Todos estos parecen ser sitios con construcciones ( $h a ́-$ bitats), pero hay muchos sitios que son sólo estancias como Ales, Ana, Calarcoco, Ocara, Talabre (Lascar), Junta, Peñalire, Salitre y San Juan (estos cuatro últimos se registran desde antes de la existencia de Río Grande), Tebenquiche aún con sus construcciones en buen estado a la orilla de la lagunita del centro-norte del Salar de Atacama y que a pesar de ser reutilizada hasta en estos últimos años, debe remontarse a una época anterior a los incas.

Si enumeramos de nuevo todos estos sitios, es para comprobar la existencia de una variedad muy clara de lo que podríamos llamar transhumancia del tipo de los cazadores ya establecidos, pero irradiando alrededor del hábitat principal; del tipo de los pastores que cazan mientras pastorean sus llamas; del tipo de los pastores que cambian sus zonas de pastoreos y que cazan más por gusto que por necesidad $\mathrm{y}$, por fin, el tipo de los pastores sin preocupación de caza, pues se trata de mujeres con sus niñitos que cuidan a los animales domésticos.
También hay que tomar en cuenta a todas las estancias modernas y abandonadas de los trabajadores de la yareta, de los investigadores del cobre o de la sal, que pueden producir equivocaciones en todos estos sistemas de "transhumancia".

¿Cuáles serían nuestras conclusiones? Por el momento la necesidad de estudiar mucho más para poder saber si se trata del desplazamiento de poblaciones o de verdadera "transhumancia": ubicación, altitud, planos, artefactos líticos, alfarería, capas de subsuelo. Pero ¿cuáles serán los elementos básicos para saber si se trata de desplazamiento de poblaciones o de "transhumancia"? Ahora podemos dar un aspecto general, una síntesis de este problema tan apasionante que abarca en nuestros Estudios Atacameños: 326 sitios del Paleolítico y 67 hábitats con estructuras. Cada uno necesitaría no un tomo, si no más.

También debemos evitar que un nuevo aspecto de los estudios arqueológicos llegue a ser tan principal en nuestra mente, como para suprimir otros aspectos. En 1963 todo se explicaba por la horizontalidad, ahora es la verticalidad que en aquella época defendíamos para la Cultura Atacameña. En pocos años quizás se diga que no existió transhumancia sino ocupación progresiva de la zona, desplazamientos de poblaciones por razones ecológicas, ¿emigración lenta de unos elementos quedándose los otros en su primer sitio de ocupación?

Entregamos todo esto a la reflexión de nuestros lectores para evitar tomas de posición apuradas y justificar también lo que llamamos las tres etapas de nuestros Estudios Atacameños.

\section{Notas explicativas}

I. El desierto aumenta:

1. Epoca colonial. Destrucción de la selva del Tamarugal al este de Iquique por la necesidad de los hornos de las industrias.

2. Actualmente. Destrucción de la yareta que provocó:

a) Las quebradas dentro de la liparita recibieron torrentes intermitentes;

b) Los valles verdes en tierras vegetales ya no tienen agua, pues en su gran mayoría se entubó en las captaciones de agua para los grandes centros de población; 
c) La escasez de agua aumentó en las vegas aun por el drenaje que no resultó, sino para secar definitivamente estas vegas.

3. Prueba de vegetación. Las llanuras de Tulan, como de toda la cordillera, reflorecen después de una lluvia anual (documentos fotográficos en mi archivo).

II. "Transhumancia" (en el sentido general):

1. De los cazadores recolectores: En el año 1957 la recolección de huevos de parinas (flamencos rosados) controlados por inspectores alcanzó la cifra de 80000 unidades. ¡Ahora la recolección es nula!

2. Cazadores: Algunos autores toman el ritmo parturial de dos años para postular una "transhumancia". Cada dos años o año por medio, en comparación con los actuales rebaños de llamas, se sale a la caza de auquénidos tomando este marco de referencia. Según estas ideas ¿no sería posible o plausible que la mitad de las hembras tenga su tiempo este año y la otra mitad en el otro año? ¿Y la transhumancia se haga en la misma estación cada año? Pero esto tampoco comprueba la "transhumancia" sino la caza estacional.

\section{Objeción y respuesta}

El estudio objetivo del asunto "ocupación de la zona" o "transhumancia" nos fuerza a preguntar ¿Existe o no? No creemos que sea necesario ser intransigente en la toma de posiciones, cuando estamos sólo en la etapa de sondeos del terreno. Esta intransigencia se manifiesta en casos de la zona atacameña:

1) “Cráneos chatos". Se postulaba un tipo ancestro neanderthaloide o parantropoide. Algunos lo rechazaron. Pero ahora ¿qué postulan como ancestros de los australianos de 25000 a 30000 años? Vean artículo en Sciences et avenir (marzo 1973), además de la correspondencia del Dr. Leakey con el autor.

2) "Complejo Chuqui": Tan controvertido... y ahora ¿qué se dirá de la más antigua industria del Omo en Etiopía? (vean el mismo número de Sciences et avenir).

3) “Cultura vertical”. Fue rechazada en los años 1961 y 1963, como lo hemos dicho anteriormente. Pero fue reemplazada por el término "culturas horizontales", y ahora fue la gran tesis del Congreso de Arqueología de Santiago (1971) y del Congreso del Hombre Andino (1973). 